\title{
Cardenio "el Rústico", el licenciado Tomé de Burguillos y el gracioso: un personaje lopesco en la Arcadia (1598) y en las Rimas de Tomé de Burguillos (1634)
}

\section{Antonio Sánchez Jiménez \\ Universidad de Neuchâtel}

Título: Cardenio "el Rústico", el licenciado Tomé de Burguillos y el gracioso: un personaje lopesco en la Arcadia (1598) y en las Rimas de Tomé de Burguillos (1634).

Resumen: La labor de reescritura tan habitual en Lope de Vega se extiende desde el comienzo hasta el fin de su carrera, como demuestra la comparación de dos personajes jocosos (Cardenio y Tomé de Burguillos) en el primer y último libro publicado por el Fénix (Arcadia y Rimas de Tomé de Burguillos). El análisis del tipo de humor de estos personajes permite además preguntarse sobre la posible influencia de los mismos en la creación de una de las innovaciones principales del arte nuevo dramático de Lope: el gracioso.
Title: Cardenio "The Peasant", Tomé de Burguillos "The graduate" and the Jester: a Lopesque Character in the Arcadia (1598) and in the Rimas de Tomé de Burguillos (1634).

Abstract: The process of rewriting that is so common in the works Lope de Vega spans since the beginning to the end of his literary career. A comparison between two of his comic characters proves it: Cardenio (from the Arcadia) and Tomé de Burguillos (from the Rimas de Tomé de Burguillos) belong to Lope's first and last book, but present obvious similarities. Analyzing their peculiar humor also allows us to inquire into one of Lope's most characteristic creations for the comedia nueva, the gracioso, on whom Cardenio and Tomé de Burguillos may very well have influenced.

Palabras clave: Reescritura, novela pastoril, Burguillos, gracioso.

Fecha de recepción: 4/4/2013.

Fecha de aceptación: 11/6/2013.
Key words: Rewriting, pastoral novel, Burguillos, gracioso.

Date of Receipt: 4/4/2013.

Date of Approval: 11/6/2013. 
Para entender la carrera literaria, e incluso el estilo, del gran Lope de Vega, existen pocos testimonios tan valiosos como un parlamento de Belardo en la comedia Si no vieran las mujeres ${ }^{1}$. En él, Belardo, habitual y conocido seudónimo del Fénix ${ }^{2}$, responde al emperador Otón, que se sorprende de verle y que al hacerlo ha exclamado un “'Aún viven Belardos?”3. A esto el aludido Belardo replica:
¿No aueis visto vn arbol viejo,
cuyo tronco (aunque arrugado)
coronan verdes renueuos?
Pues esso aueis de pensar,
y que passando los tiempos,
yo me sucedo à mi mismó .

Como afirma aquí su seudónimo, Lope estaba hecho a renovarse durante su larga carrera, alterando su imagen pública para adaptarse a las cambiantes circunstancias sociales y literarias ${ }^{5}$. Además de esa imagen, el Fénix reutilizaba frecuentemente sus propios temas, palabras e incluso versos, como ha venido notando la crítica lopesca. Así, Alan Trueblood demostró que Lope había ido retomando y desarrollando el tema de su relación con Elena Osorio a lo largo de su carrera ${ }^{6}$. De modo más concreto, lopistas

1 Esta comedia apareció impresa en La vega del Parnaso, que salió póstuma en 1637. Griswold Morley y Courtney Bruerton consideran que Lope debió de escribir la obra hacia 1631 o 1632, Griswold Morley y Courtney Bruerton, Cronología de las comedias de Lope de Vega. Con un examen de las atribuciones dudosas, basado todo ello en un estudio de su versificación estrófica, trad. M.R. Cartes, Madrid, Gredos, 1968, p. 396.

2 Sobre éste y otros seudónimos del poeta conviene consultar el clásico artículo de Griswold Morley, "The Pseudonyms and Literary Disguises of Lope de Vega", University of California Publications in Modern Philology, XXXVIII (1951), pp. 21-84.

3 Lope de Vega, Si no vieran las mujeres, La vega del Parnaso, Madrid, Imprenta del Reino, 1637, ff. 265r-292v (f. 276r).

4 Ibidem, f. 276v.

5 Antonio Sánchez Jiménez, Lope pintado por sí mismo. Mito e imagen del autor en la poesía de Lope de Vega Carpio, Londres, Tamesis, 2006.

6 Alan S. Trueblood, Experience and Artistic Expression in Lope de Vega: The Making of La Dorotea, Cambridge, Harvard University Press, 1974. 
tan ilustres como Fernando Lázaro Carreter ${ }^{7}$, José F. Montesinos ${ }^{8}$, Edwin Morby $^{9}$, Maurice Molho ${ }^{10}$ o Antonio Carreño ${ }^{11}$ han estudiado la reaparición de un tema y fraseología (la de los "mansos") en diversas obras del madrileño. La crítica incluso ha notado la reutilización de palabras e imágenes concretas (el vocabulario de la tormenta naval, el “taratántara”), que Lope emplearía con intervalos tan amplios como los que van de sus primeros romances a La Gatomaquia, en las Rimas de Tomé de Burgui$l l o s^{12}$. Acompañando a estos datos, los estudiosos han avanzado algunas hipótesis sobre los motivos de la constante reescritura lopesca. Así, Juan Manuel Rozas la ha localizado especialmente en el ciclo de senectute, los tristes años finales del poeta, y la ha relacionado con una nostalgia provocada por una crisis vital ${ }^{13}$. Una explicación alternativa, y especialmente adecuada para entender el fenómeno en géneros diversos, como la obra dramática del Fénix, es la que ofrece Felipe Pedraza Jiménez: la reescritura

7 Fernando Lázaro Carreter, "Lope, pastor robado", en Günter Reichenkron y Erich Haase (ed.), Formen der Selbstdarstellung: Analekten zu einer Geschichte des literarischen Selbstportraits. Festgabe für Fritz Neubert, Berlín, Duncker \& Humblot, 1956, pp. 209-224.

8 José F. Montesinos, Estudios sobre Lope de Vega, Salamanca, Anaya, 1967, pp. 140-141.

9 Edwin S. Morby, “Two Notes on La Arcadia”, Hispanic Review, XXXVI (1968), pp. 110-23 (pp. 110-115).

10 Maurice Molho, "Teoría de los mansos: un triple soneto de Lope de Vega", Bulletin Hispanique, XCIII (1991), pp. 135-155.

11 Antonio Carreño, ed., Rimas humanas y otros versos, de Lope de Vega Carpio, Barcelona, Crítica, 1998, p. 83; pp. 359-360; p. 858.

12 Antonio Sánchez Jiménez, "Pedro de Oña y su Arauco domado (1596) en la obra poética de Lope de Vega: notas sobre el estilo de Lope entre el 'taratántara' y las 'barquillas', Hispanic Review, CLXXIV (2006), pp. 319-44.

13 Juan Manuel Rozas, Estudios sobre Lope de Vega, Madrid, Cátedra, 1990. Aunque la hipótesis de Rozas está muy difundida, se basa en una correlación entre biografía y literatura que puede resultar arriesgada, y que además funciona mejor en modalidades literarias más proclives a la ilusión biográfica, como la lírica, en la que de hecho se centra el estudio de Rozas. Para una revisión moderna de la circunstancias del ciclo de senectute y de sus consecuencias para el teatro lopesco conviene consultar el estudio de Joan Oleza, "Las opciones dramáticas de la senectud de Lope, en José María Díez Borque y José Alcalá Zamora (ed.), Proyección y significados del teatro clásico español, Madrid, SEACEX, 2004, pp. 257-276. 
(el uso de fórmulas retóricas y temáticas) no estaría limitada a los últimos años del autor. Más bien, se extendería por toda su carrera y sería una respuesta de Lope a la insaciable demanda del mercado teatral ${ }^{14}$. Fuera cual fuere la explicación y el género al que queramos aplicarla, lo cierto es que la reescritura, lo que hemos denominado reciclaje, es un fenómeno esencial en la obra de Lope, tanto en la producción teatral como en la no dramática.

En este trabajo pretendemos completar el panorama crítico en sus dos vertientes complementarias, la empírica y la hermenéutica. Para ello aportamos primeramente nuevos datos en torno al fenómeno de la reescritura en Lope, centrándonos en el primer y último libro que publicó el autor: la Arcadia (1598) y las Rimas de Tomé de Burguillos (1634). Nuestro estudio muestra cómo el personaje y la modalidad literaria que Lope desarrolló en el Burguillos es una evolución de elementos que exploró con anterioridad en la Arcadia. Además, y en segundo lugar, examinamos las consecuencias que tiene este descubrimiento para comprender la carrera de Lope en general y su cultivo ambidextro de la poesía teatral y dramática en particular. Para ello, expondremos para empezar la génesis del personaje de Tomé de Burguillos tal y como se conoce hasta hoy, resumiendo las características que los críticos encuentran en él y en su contexto, el ciclo de senectute. A continuación, compararemos ese personaje y características con el de Cardenio "el Rústico", de la Arcadia. Por último, interpretaremos este cotejo enfatizando la importancia para la carrera del autor de la estancia de Lope en Alba de Tormes. Teniendo en cuenta este contexto, reflexionaremos sobre el papel de la experiencia teatral y libresca en el resto de la obra del Fénix. Ya desde este punto de vista examinaremos el papel de Cardenio el Rústico en la renovación lopesca de la novela pastoril y de la lírica áurea en la Arcadia y las Rimas de Tomé de Burguillos, respectivamente.

La conexión que sugerimos entre Cardenio y Burguillos es la más profunda de otra serie de similitudes entre la Arcadia y las Rimas de Tomé de Burguillos, pues existe una serie de ecos textuales que ya sugieren un vínculo entre los libros. El ejemplo más claro es una parodia de un soneto

14 Felipe B. Pedraza Jiménez, Lope de Vega, genio y figura, Granada, Universidad, 2008. 
de la Arcadia, el titulado "Celso, al peine de Clavelia"15, que en 1634 Burguillos convierte en el soneto "A un peine que no sabía el poeta si era de boj o de marfil"16. El tema del poema de la Arcadia se ha hecho famoso gracias a un admirable soneto de Quevedo ("En crespa tempestad del oro undoso" $)^{17}$, que este poeta imitó de segunda mano, probablemente vía Marino $^{18}$. Sin embargo, la maestría de Quevedo no debe hacernos olvidar que Lope parodió su propio soneto de la Arcadia en el Burguillos. Esto sugiere ya que el proceso de reescritura general que suponen las Rimas de Tomé de Burguillos toca también material procedente de la Arcadia. Es decir, un vínculo concreto une los dos volúmenes, vínculo que se debe encontrar, sugerimos, en la relación entre Cardenio y Burguillos.

Como hemos anticipado, las Rimas de Tomé de Burguillos surgen de la reescritura de textos previos de Lope. Por ello resulta especialmente interesante el hecho de que el personaje de Burguillos, tal y como hasta hoy lo conocemos, sea producto ya de un semejante y complejo aprovechamiento de materiales previos ${ }^{19}$. Para empezar, las Rimas de Tomé de Burguillos se basan en una reescritura lato sensu: el apellido del heterónimo ${ }^{20}$ se asienta en las ya existentes connotaciones de la palabra "Burguillos". Y es que Burguillos es un pueblo toledano que evocaría el tono alegre del libro (Burguillos era célebre por su vino) y el obsesivo tema del mecenazgo que lo atraviesa (el señor de Burguillos era el duque de Béjar, mecenas de las letras). Además, Burguillos era también el nombre de varios poetas del momento, los ecos de cuyas obras Lope aprovecha en 1634. Así, había un Burguillos del Cancionero de Amberes que versifica la leyenda de Bernardo del Carpio, tan rica en alusiones lopescas. Asimismo, Tomé de Burguillos

15 Lope de Vega, Arcadia, ed. Antonio Sánchez Jiménez, Madrid, Cátedra, 2012, ff. $184 \mathrm{v}-185 \mathrm{r}$.

16 Lope de Vega, Rimas de Tomé de Burguillos, ed. Macarena Cuiñas Gómez, Madrid, Cátedra, 2008, núm. 15.

17 Francisco de Quevedo, Un Heráclito cristiano, Canta sola a Lisi y otros poemas, ed. Lía Schwartz e Ignacio Arellano, Barcelona, Crítica, 1998, núm. 111.

18 Lía Schwartz e Ignacio Arellano (ed.), Un Heráclito cristiano, Canta sola a Lisi y otros poemas, de Francisco de Quevedo, Barcelona, Crítica, 1998, p. 180.

19 Antonio Sánchez Jiménez resume la prehistoria del personaje, Lope pintado, op. cit., pp. 182-190.

20 Juan Manuel Rozas, "Burguillos como heterónimo de Lope”, Edad de Oro, IV (1985), pp. 139-63. 
nos recuerda al poeta toledano Juan de Burguillos (1512-1575) ${ }^{21}$, bastante conocido en la época (Fernando de Herrera cita completa una estrofa suya en sus difundidas Anotaciones) ${ }^{22}$. Concretamente, Juan de Burguillos era famoso por su mala fortuna y por su capacidad de improvisación ${ }^{23}$, circunstancias ambas que Lope (y Burguillos) consideraba como propias. Además, Juan era reprendido por su obra jocosa ${ }^{24}$, precisamente el género en que sobresale Tomé de Burguillos. Menos evidente es la relación del personaje con otros tres Burguillos del momento: un famoso loco $^{25}$, un poeta franciscano (que podría anticipar la vena sacra de Tomé), y un estudiante que evocaría la supuesta etapa de Burguillos en las aulas salmantinas ${ }^{26}$.

De modo mucho más directo, las Rimas de Tomé de Burguillos son producto de un proceso de reescritura de obras previas del propio Lope. Y es que el texto que lanzó a Burguillos a la fama es un volumen mixto cuyo marco y heterónimo (el licenciado Tomé de Burguillos) son una ficción que Lope aprovecha para lanzar textos escritos antes de $1634^{27}$. Es

21 Alberto Blecua, "Juan Sánchez Burguillos, ruiseñor menesteroso del siglo XVI”, en Manuel Alvar López et alii (ed.), Estudios sobre el Siglo de Oro. Homenaje al profesor Francisco Ynduráin, Madrid, Editora Nacional, 1984, pp. 69-85.

22 Fernando de Herrera, Anotaciones a la poesía de Garcilaso, ed. Inoria Pepe y José María Reyes, Madrid, Cátedra, 2001, p. 726.

23 Herrera le consideraba "dino de ser estimado entre los mejores poetas españoles, si la miseria de su fortuna no le hiziera tanto impedimento", Fernando de Herrera, op. cit., p. 726. Otro comentarista de la época, Juan Rufo, le califica de "decidor de repente", Juan Rufo, Las seiscientas apotegmas y otras obras en verso, ed. Alberto Blecua, Madrid, Espasa-Calpe, 1972, p. 256. A su vez, también el toledano Sebastián de Horozco le define de modo semejante como un "trovador de repente", Antonio Carreño, "Los engaños de la escritura: las Rimas de Tomé de Burguillos, de Lope de Vega", en Manuel Criado de Val (ed.), Lope de Vega y los orígenes del teatro español. Actas del I Congreso Internacional sobre Lope de Vega, Madrid, Edi-6, 1981, pp. 547-563 (pp. 551-553).

24 Se trata de un comentario de Juan de Caramuel que recoge Antonio Carreño, "Los engaños", op. cit., p. 553.

25 Felipe Antonio Lapuente, "Más sobre los seudónimos de Lope de Vega", en Manuel Criado de Val (ed.), op. cit., pp. 657-669.

26 Antonio Sánchez Jiménez, Lope pintado, op. cit., pp. 189-190.

27 Joaquín de Entrambasaguas considera que muchos de los poemas de la colección fueron escritos entre 1605 y 1610, Joaquín de Entrambasaguas, Lope de Vega y 
decir, las Rimas de Tomé de Burguillos son un marbete que funciona como receptáculo de poemas anteriores o de versos reescritos. Por ejemplo, la canción "Murmuraban al poeta la parte donde amaba por los versos que hacía" ${ }^{28}$, incluida en la colección, es una versión de una ya publicada en la Primera parte de Flores de poetas ilustres de España (1605), de Pedro Espinosa $^{29}$. Además, el personaje de Burguillos ya había aparecido en obras anteriores a la compilación de 1634. Estos libros estaban ligados a festejos públicos, las Justas poéticas a la beatificación de santa Teresa (1614) y los que solemnizaron la beatificación y canonización de san Isidro, en 1620 y 1622, respectivamente ${ }^{30}$. Lope se encargó de organizar los festejos y concurrió a los mismos con varias composiciones, unas bajo su nombre y otras bajo el jocoso seudónimo de Tomé de Burguillos ${ }^{31}$. El Fénix incluso utilizó a Burguillos en otras ocasiones festivas, como la que recoge Pedro José Pidal, y que alude a una reconciliación entre Lope y Quevedo. Para celebrarla, Burguillos compuso la siguiente redondilla:

Hoy hacen amistad nueva, más por Baco que por Febo, don Francisco de Que-bebo con el gran Lope de Beba ${ }^{32}$.

De hecho, en las Rimas de Tomé de Burguillos encontramos alusiones directas a esa regocijada historia previa del personaje, y por tanto al hecho

su tiempo, v. 1, Barcelona, Teide, 1961, p. 219. Por su parte, otros autores, como Antonio Iglesias Laguna, "Bernardino de Albornoz y su antilopesco poema La Gaticida famosa", Cuadernos hispanoamericanos (Homenaje a Lope de Vega), CLXILXII (1963), pp. 647-672, o Felipe B. Pedraza Jiménez, "La Gatomaquia, parodia del teatro de Lope”, en Manuel Criado de Val (ed.), op. cit., pp. 564-589, p. 570, se inclinan por un momento más cercano a la publicación de libro.

28 Lope de Vega, Rimas de Tomé, pp. 427-438.

29 Antonio Sánchez Jiménez, Lope pintado, p. 217. Macarena Cuiñas Gómez (ed.), op. cit., p. 427. Antonio Carreño (ed.), Rimas de Tomé de Burguillos, de Lope de Vega, Salamanca, Almar, 2002, p. 363. Juan Manuel Rozas y Jesús Cañas Murillo (ed.), Rimas de Tomé de Burguillos, de Lope de Vega, Madrid, Castalia, 2005, p. 338.

30 Antonio Sánchez Jiménez, Lope pintado, p. 190.

31 Macarena Cuiñas Gómez (ed.), pp. 21-22.

32 P. José Pidal, “¿Tomé de Burguillos y Lope de Vega, son una misma persona?”, Estudios literarios, Madrid, M. Tello, 1890, II, pp. 177-191 (p. 184). 
de que el volumen supone una reescritura de textos anteriores. Así, en el "Advertimiento al señor lector" Lope, que se presenta como el editor de la obra, señala que Burguillos

no es persona supuesta, como muchos presumen, pues tantos aquí le conocieron y trataron, particularmente en los premios de las Justas, aunque él se recataba de que le viesen, más por el deslucimiento de su vestido que por los defectos de su persona; y asimismo en Salamanca, donde yo le conocí y tuve por condicípulo, siéndolo entrambos del doctor Picardo el año que llevó la cátreda el doctor Vera ${ }^{33}$.

Con este juego literario Lope anticipa uno de los mecanismos cómicos centrales de la obra: la paradoja de que, al enfatizar la existencia del personaje, se atrae la atención del lector hacia el hecho de que Burguillos es una ficción ${ }^{34}$. Es la impresión que además confirman ciertas alusiones jocosas del pasaje citado, bromas sobre dos hechos consabidos por Lope y su público: Burguillos no se dejaba ver en las justas porque le daba vergüenza que vieran su pobre vestido (con esto el Fénix llama la atención al tema de la pobreza de los poetas) pero Lope le conoció en Salamanca, donde estudiaron juntos (el Fénix no tenía ningún título universitario, y menos de Salamanca). En cualquier caso, indirecta o directamente, el personaje de Burguillos y las Rimas de Tomé de Burguillos se construyen en gran parte mediante la reescritura de temas y textos anteriores, y la Arcadia se encuentra entre estas obras previas que se reciclan en 1634.

De hecho, las características que la crítica moderna ha notado en Burguillos se basan también en el hecho de que el personaje es una especie de reescritura: Burguillos es una autoparodia diseñada por el Fénix, una

33 Lope de Vega, Rimas de Tomé, p. 110.

34 Los juegos sobre la identidad del heterónimo son parte esencial de las Rimas de Tomé de Burguillos. Valgan como ejemplo las dudas sobre las atribuciones de algunos poemas, como el dedicado a una pulga, que se titula "La pulga, falsamente atribuida a Lope" (núm. 95), o un diálogo entre Burguillos y Lope en que el primero se disculpa de su estilo jocoso: "Discúlpase con Lope de Vega de su estilo" (núm. 134) y luego "Prosigue la misma disculpa" (135), Lope de Vega, Rimas de Tomé. Sobre el poema número 97 conviene consultar el reciente trabajo de Carlos Brito Díaz, "Campos de aljófar siembras de granates. A propósito del elogio paradójico en Lope de Vega”, eHumanista, XV (2010), pp. 251-261. 
exhibición autoconsciente del modo en que Lope construía sus diversas máscaras poéticas. Se trata, como apunta Isabel Torres, de un proceso de "ventriloquización" por el que Lope se transforma en su heterónimo Tomé de Burguillos ${ }^{35}$. Una de las primeras indicaciones de ello es que el retrato que presenta el volumen, ostentosamente para demostrar de una vez por todas que Burguillos es una persona real, y no un disfraz del propio Fénix, es precisamente una caricatura del poeta madrileño.

El supuesto retrato de Burguillos, afirma Lope, "se copió de un lienzo en que le trasladó al vivo el catalán Ribalta, pintor famoso entre españoles de la primera clase" 36 . Sin embargo, la prometida "fisionomía" de Burguillos parece más bien la de un Lope joven y gordo, vistiendo ropas de licenciado, coronado de laureles - o quizás tomillos, como asevera cómicamente uno de los sonetos del libro ${ }^{37}$ - y enmarcado en una caprichosa fantasía arquitectónica. Se trata de una parodia de los retratos que el Fénix incluía en sus obras impresas ${ }^{38}$. El retrato es, por tanto, un adecuado anticipo de la parodia de la carrera de Lope que Burguillos llevará a cabo en el resto de la obra ${ }^{39}$.

Y es que los textos de las Rimas de Tomé de Burguillos parodian las diversas facetas y estilos que Lope había asumido hasta el momento ${ }^{40}$. Así lo expresó Rozas, para quien en el ciclo de senectute en general, y en las Rimas de Tomé de Burguillos en particular, Lope trata de efectuar un "cambio

35 Isabel Torres, "Interloping Lope: Transformation and Tomé de Burguillos", Bulletin of Spanish Studies, LXXXV (2008), pp. 273-288.

36 Lope de Vega, Rimas de Tomé, pp. 111-112.

37 Ibidem, p. 114.

38 Antonio Sánchez Jiménez, Lope pintado, pp. 223-227.

39 Según Mercedes Blanco, la persona de Burguillos se construye en los diez primeros sonetos de la obra. Cf. Mercedes Blanco, "La agudeza en las Rimas de Tomé de Burguillos", en Maria Grazia Profeti (ed.), en "Otro Lope no ha de haber". Atti del convegno internazionale su Lope de Vega. 10-13 febbraio 1999, v. 1, Alinea, 2000, pp. 219-40, p. 221. Sin embargo, y como se ha podido comprobar en nuestro análisis de los textos previos a 1634, y de los preliminares -el "Advertimiento" y el retrato-, creemos que, aunque esos diez sonetos son esenciales, la figura del heterónimo se forja antes de la colección de 1634, y luego a lo largo de todo el libro, desde el prólogo hasta las "Rimas divinas" finales.

40 Antonio Sánchez Jiménez, Lope pintado, pp. 191-219. 
de imagen" típico de un "escritor falsificador de autobiografismo" El cambio de imagen es consciente y casi explícito, pues se transforma de autobiografía en autoparodia. Es por ello que surgen, del juego de relaciones intertextuales entre el heterónimo y su creador, las características esenciales de Burguillos y del volumen de 1634. En primer lugar, los poemas del heterónimo remedan jocosamente cancioneros petrarquistas como las Rimas de Lope, y por tanto la imagen de enamorado que difundió el Fénix al comienzo de su carrera. De ese Lope Burguillos tiene la pobreza, la pasión y el estilo, pero se burla de esa imagen cuando subraya las necesidades físicas frente al amor ideal, y cuando pone en evidencia -y así ridiculiza- las convenciones del petrarquismo. En segundo lugar, la pobreza y falta de pretensiones de Burguillos parodian las ínfulas de grandeza de Lope: Burguillos exhibe una pobreza ignominiosa que hace que le confundan con un mendigo ${ }^{42}$. En tercer lugar, Burguillos ha renunciado a obtener un mecenazgo como el que persiguió el Fénix: Burguillos espera morir pobre como el glorioso portugués Luis de Camões ${ }^{43}$, tan pobre que, afirma con ironía el heterónimo, llegue a parecer virtuoso ${ }^{44}$. En cuarto lugar, Burguillos ridiculiza la imagen de poeta genial que fomentó Lope desde el Isidro: como observamos en el supuesto retrato, Burguillos degrada continuamente el símbolo del genio y gloria poética, el laurel ${ }^{45}$. En quinto lugar, Burguillos imita la posición de Lope como poeta archiespañol, defensor del estilo llano y castellano frente a la herejía poética de Góngora y sus cultos. Burguillos no ridiculiza los ataques de Lope contra los poetas nuevos, sino que más bien los adopta, insistiendo más que el Fénix en el tono burlesco que le caracteriza. Así, Burguillos se pelea con su pluma, que le ha salido gongorina ${ }^{46}$, parodia el estilo de los $\operatorname{cultos}^{47}$, o les censura por no hablar "como la Patria manda" 48 . Además de

41 Juan Manuel Rozas, Estudios, p. 80 (p. 74).

42 Lope de Vega, Rimas de Tomé, p. 204 (p. 218).

43 Ibidem, p. 317.

44 Ibidem, p. 218.

45 En el libro el laurel es más útil como condimento que como símbolo, Lope de Vega, ibidem, p. 129; p. 161.

46 Ibidem, p. 173.

47 Ibidem, p. 214 (p. 348).

48 Ibidem, p. 228. 
estas críticas metaliterarias, y en sexto lugar, Burguillos sigue el modelo lopesco al escribir poesía religiosa -el libro incluye unas "Rimas divinas", menos importantes que las "humanas" ${ }^{39}$ - y poesía moral de corte neoestoico, como la que expresa que Burguillos se consuela con sus "dos libros, tres pinturas, cuatro flores" 50 de la envidia que provoca.

En suma, y como muestran estas seis características centrales, Burguillos parodia a Lope en poses y estilo, lo que le otorga al libro de 1634 un claro tono irónico, paródico y autorreferente. A este estilo peculiar y casi único en la lírica del siglo XVII ${ }^{51}$ debemos añadir un gusto desengañado típico del momento, que la crítica relaciona con los reveses vitales que Lope experimentó en su ciclo de senectute ${ }^{52}$. Como resume Pedraza Jiménez, la situación del viejo poeta en los años de escritura y publicación de las Rimas de Tomé de Burguillos era difícil: "Las guerras literarias, donde no lleva la mejor parte, y la lucha por alcanzar el favor cortesano y un cargo oficial, resuelta en un fracaso, atemperado por encargos ocasionales, se alían con su difícil situación familiar para dejar en su alma un poso de melancolía"53. Lope experimentaba una angustiosa mezcla de adversidades profesionales y personales que muy bien pudieron contribuir al tono de humor negro, al sabor jocoso-desengañado del libro. Sin embargo, y curiosamente, estas características aparecían ya en la época de juventud del Fénix: se dejan notar precisamente en el personaje y texto que proponemos como antecesores de Burguillos y sus Rimas, Cardenio "el Rústico", de la Arcadia (1598).

49 Ignacio García Aguilar, Imprenta y literatura en el Siglo de Oro. La poesía de Lope de Vega, Madrid, Del Orto, 2006, p. 42. Juan Manuel Rozas, Estudios, p. 203.

50 Lope de Vega, Rimas de Tomé, núm. 161, v. 14.

51 Como único y superior a las "fuerzas humanas" le caracterizaba, al menos, Manuel de Faria y Sousa, Manuel Herrero García, Estimaciones literarias del siglo XVII, Madrid, Voluntad, 1930, p. 123. Este tono admirativo todavía prevalece entre la crítica contemporánea: Antonio Carreño define el libro como "mutatis mutandis, el Quijote de la lírica del XVII: ejemplar y único por contradictorio, paradójico y perverso”, Antonio Carreño, "Introducción", Rimas humanas y divinas del licenciado Tomé de Burguillos, ed. Antonio Carreño, Salamanca, Almar, 2002, pp. 9-115 (pp. 16-17).

52 Juan M. Rozas, Estudios, pp. 112-114. Felipe Pedraza Jiménez, "El desengaño barroco en las Rimas de Tomé de Burguillos", Anuario de Filología, IV (1978), pp. 391-418.

53 Felipe Pedraza Jiménez, El universo, p. 198. 
Lope escribió su Arcadia en unas circunstancias diametralmente opuestas a las que rodearon a las Rimas de Tomé de Burguillos, pues el libro de 1598, el primero que dio a la imprenta el Fénix, suponía un ambicioso intento de tomar al asalto el mundo literario madrileño. Era una época llena de esperanzas para el todavía joven escritor, que pudo incluso haber concebido la Arcadia como la primera entrega de una impactante tríada virgiliana (Arcadia, La Dragontea, Isidro) que le coronara como el principal poeta del momento ${ }^{54}$. Nada más opuesto, pues, al contexto de 1634, lo que no obsta para que en la Arcadia encontremos a un personaje singularmente semejante a Burguillos. Se trata, como ya hemos anunciado, de Cardenio, apodado "el Rústico", un alegre e inteligente pastor que es amigo del protagonista, Anfriso: "Cardenio, que de todas aquellas riberas era llamado "el Rústico", cuyos donaires e inocencias se celebraban por únicas" " Como los otros pastores de la Arcadia, "el Rústico" es poeta e interpreta durante el libro varias composiciones de su cosecha. Ello facilita la más importante conexión entre Burguillos y "el Rústico": si Burguillos parodiaba los poemas amorosos que cultivó, entre otros, Lope, Cardenio se burla constantemente de las convenciones en las que se basa la lírica petrarquista. Por ejemplo, los dos personajes ridiculizan la idea del sufrimiento del amante, y además lo hacen empleando las mismas dos técnicas centrales: la reducción al absurdo y la carnavalización. En el caso de Burguillos, uno de los ejemplos clave es el soneto 40, titulado "Encarece su amor para obligar a su amada a que lo premie". Este título es ya una referencia jocosa, pues pretende denunciar la muy concreta intención que albergan los poetas cuando describen su patética condición: obtener de la amada una recompensa amorosa. ${ }^{56}$ Se trata, pues, de

54 Carlos M. Gutiérrez, La espada, el rayo y la pluma. Quevedo y los campos literario y del poder, West Lafayette, Purdue University Press, 2005, p. 134. Elizabeth R. Wright, "Virtuous Labor, Courtly Laborer: Canonization and a Literary Career in Lope de Vega's Isidro", MLN, CXIV (1999), pp. 223-40, p. 228. Elizabeth R. Wright, From Pilgrimage to Patronage. Lope de Vega and the Court of Philip III, 1598-1621, Lewisburg, Bucknell University Press, 2001, p. 34.

55 Lope de Vega, Arcadia, f. 38r.

56 También Cardenio reconoce descarnadamente su propósito en la Arcadia, hablando sobre las lágrimas masculinas. Al Rústico no le parecen bien, salvo en caso de poder usarse para conquistar a una dama. En ese caso, las acepta, pero mejor si son fingidas, pues tienen el mismo efecto que las reales con menor pena. Cardenio llega incluso a 
una carnavalización de la estética petrarquista, pues Burguillos rebaja ${ }^{57}$ y reduce al plano corporal las bellas abstracciones sobre el sufrimiento amoroso que pueblan la lírica amorosa del Siglo de Oro. Los versos del soneto confirman esta intención paródica, pues se burlan de la enfermedad de amor con una reducción al absurdo de sus tópicos:
Juana, mi amor me tiene en tal estado que no os puedo mirar cuando no os veo, ni escribo, ni manduco, ni paseo, entretanto que duermo sin cuidado ${ }^{58}$.

Burguillos le describe a su irrisoria amada, la lavandera Juana (denigración carnavalesca de las damas petrarquistas), su triste estado, pues amor le ha privado de la vista y le impide escribir, comer y pasear. Se trata de quejas convencionales de los que padecen la enfermedad de amor y por tanto son típicas de los amantes desdichados que pululan en la lírica áurea. Para expresarlas, Burguillos escoge un vocabulario jocoso que rompe intencionalmente el decoro ("manduco"), y además ridiculiza con perogrulladas los clichés que suponen: no puede ver a la amada cuando no la tiene delante, ni puede realizar ninguna otra actividad mientras duerme tranquilamente ("sin cuidado"). Este rebajamiento de las convenciones de la lírica del momento continúa en el segundo cuarteto. En él reaparecen las palabras poco decorosas ("derrienga") y encontramos, además, unas muy prosaicas quejas del amante:

Por no tener dineros no he comprado (joh Amor cruel!) ni manta, ni manteo,

confesar provocarlas "untándome los ojos con toronja", Lope de Vega, Arcadia, op. cit., f. 39v. Como luego estudiaremos, este rebajamiento grotesco de los tópicos de la lírica amorosa es típico del Rústico, tanto como de Burguillos.

57 Sobre el sentido bajtiniano de este rebajamiento o degradación, Mikhail Bakhtin, Rabelais and His World, trad. H Iswolsky, Cambridge, MA, The Massachusetts Institute of Technology, 1968, pp. 19-12. Conviene consultar el estudio de Alfredo Hermenegildo, Juegos dramáticos de la locura festiva. Pastores, simples, bobos y graciosos del teatro clásico español, Barcelona, Oro viejo, 1995, p. 14.

58 Lope de Vega, Rimas de Tomé, núm. 40, vv. 1-4. 
tan vivo me derrienga mi deseo

en la concha de Venus amarrado 59 .

Las protestas de pobreza resultan absolutamente contradictorias con el mundo que evoca la cita de Garcilaso en el verso 8 del poema. Sin embargo, son omnipresentes en las Rimas de Tomé de Burguillos, relacionadas con el tema de la escasez de mecenazgo para los poetas, que estudiaremos más adelante. Igualmente típica del libro es la referencia metaliteraria provocada por la alusión intertextual del verso 8 . Y es que la cita de Garcilaso da pie en los primeros versos del primer cuarteto a un jocoso excursus:

De Garcilaso es este verso, Juana, todos hurtan, paciencia, yo os le ofrezco ${ }^{60}$.

Frente a la imitación sutil, plena de sprezzatura ${ }^{61}$, que caracterizaba la tradición petrarquista, Burguillos alude descarnadamente a la procedencia del verso, interrumpiendo para ello su reflexión y quejas amorosas, que dan ahora lugar a reproches literarios contra los cultos (a los que Burguillos acusa de envidiosos y plagiarios), tema al que volveremos más adelante. El propio Burguillos regresa bruscamente al concepto central ("mas volviendo a mi amor, dulce tirana"), tras lo que remata el soneto con una nueva degradación del amor ideal:

tanto en morir y en esperar merezco, que siento más el verme sin sotana, que cuanto fiero mal por vos padezco ${ }^{62}$.

En suma, los sufrimientos físicos que la pobreza le ocasiona a Burguillos, que no tiene ni para sotana, superan los padecimientos espirituales que le causa el amor. Se trata de una inversión total de los valores propios

59 Ibidem, núm. 40, vv. 5-8.

60 Ibidem, núm. 40, vv. 9-11.

61 Ignacio Navarrete, Los huérfanos de Petrarca. Poesía y teoría en la España renacentista, trad. Antonio Cortijo Ocaña, Madrid, Gredos, 1997, pp. 72-73.

62 Lope de Vega, Rimas de Tomé, núm. 40, vv. 12-14. 
de la lírica del momento, en la que el alma y lo espiritual eran siempre superiores al cuerpo y lo material.

Este estilo y temática de las Rimas de Tomé de Burguillos, que los comentaristas han calificado de únicos y típicos del ciclo de senectute, había aparecido ya en la Arcadia. En esa obra Cardenio recita varios poemas jocosos, a menudo caracterizados por ridiculizar las convenciones de la lírica amorosa que preñan la obra en general y los poemas de los otros pastores que pueblan el libro en particular. Así, por ejemplo, cuando los pastores tienen que componer versos con ocasión de una prenda recibida de las pastoras, el Rústico escribe unas cuartetas y quintillas "Al prendedero de Marfisa". En ellas Cardenio se retrata como un amante ingenuo, propicio a la interpretación literal, pues piensa que, puesto que Marfisa ha entregado su prendedero, la bella ya no podrá cautivar o prender con sus encantos a los que la miran. Por tanto, el Rústico invita a los pastores a venir a ver

sin miedo de padecer

prisión, desdenes y enojos,

de mi pastora los ojos,

que ya no pueden prender $^{63}$.

El "rústico" entusiasmo de Cardenio llega a tal extremo que cree encarnar al amor y poseer su poder, o al menos ser su ministro:

Pastores, yo soy amor,

yo prendo, yo doy favor;

veis el prendedero aquí,

que ya no me prende a mí,

para que prenda mejor.

Por justicia me declara:

prenderos puedo si quiero.

Veis aquí el título y vara:

éste fue su prendedero ${ }^{64}$.

63 Lope de Vega, Arcadia, f. 185r.

64 Ibidem, f. 185r. 
Esta ingenua ilusión se desvanece al final del poema, cuando "el Rústico" se da cuenta de su error y nos indica cuál es la reacción más apropiada ante su canto:

¡Qué engañado me alabé!

No en balde el Rústico fui, pues tal gloria imaginé que pudo caber en mí.

Pastores, cese la risa; el que os engaña os avisa que prende como primero, porque es éste el prendedero de las sayas de Marfisa ${ }^{65}$.

Los receptores intradiegéticos, los "pastores" a los que apela Cardenio, deben reírse ante estas humoradas, y otro tanto deben hacer los receptores extradiegéticos, los lectores. Como Burguillos, "el Rústico" desempeña un papel burlesco y paródico, un contrapunto a la lírica amorosa que, en la Arcadia, emplean los idealizados pastores que le rodean.

Estas características son propias de todas las composiciones del Rústico ${ }^{66}$, pero aparecen exacerbadas en el más extenso poema que Cardenio canta en el libro. Se trata de una serie de cuartetas hexasilábicas que entona de camino a la cueva de la maga Polinesta, un poema demasiado largo (96 versos) como para que lo citemos por completo, pero que debemos analizar por ser uno de los más representativos del personaje. El texto comienza ridiculizando las típicas antítesis petrarquistas ${ }^{67}$ mediante unas

65 Ibidem, f. $185 \mathrm{v}$.

66 Valga como ejemplo el poema definiendo amor que canta a petición de Frondoso y Galafrón, que ante la tristeza de Anfriso le habían rogado a Cardenio "que le divirtiese a su gracioso modo", Lope de Vega, ibidem, f. 229r. En él, el Rústico toma una especialidad de Lope, las definiciones de amor, y la ridiculiza con su jocoso estilo.

67 Leonard Forster, The Icy Fire: Five Studies in European Petrarchism, Londres, Cambridge University Press, 1969. Edward M. Wilson y Arthur L. F. Askins, "History of a Refrain: 'De la dulce mi enemiga", MLN, LXXXV (1970), pp. 138-156. 
comparaciones prosaicas y ridículas y unos encarecimientos que resultan no ser tales:
Pastora enemiga, agradable y fiera, blanda como ortiga, dura como cera ${ }^{68}$.

La segunda cuarteta anuncia ya el tema central de la composición: la descripción del triste estado al que los desdenes de la dama han llevado al poeta. Se trata, pues, de nuevo de la enfermedad de amor, que Cardenio ridiculiza usando precisamente los mecanismos que examinamos arriba en el soneto de Burguillos: la reducción al absurdo y la carnavalización.
ya de tus engaños
vengo a estar de suerte
que al fin de mis años
me llama la muerte.
En esta partida, de tu amor incierto, ya no quiero vida en estando muerto ${ }^{69}$.

Como haría años más tarde Burguillos, el Rústico parodia y ridiculiza con perogrulladas la muerte por amor, pues más que los desdenes de la dama es el fin de sus días el que traerá la muerte al poeta. Estas bromas resumen el espíritu del poema, pues en las cuartetas siguientes descubrimos que el Rústico ha llegado a tal punto de desesperación que no puede andar, comer, o dormir, pero no, claro está, por culpa de su rabioso amor, como cabría esperar según las pautas de las convenciones petrarquistas: Cardenio no puede andar cuando está "sentado", comer cuando no tiene hambre ("gana”), o dormir cuando está “velando". De modo semejante,

68 Lope de Vega, Arcadia, f. 269r.

69 Ibidem, f. 269r. 
la cruel dama hace que "el Rústico"reaccione de modo peculiar ante las inclemencias del tiempo:

Por ti, en el invierno, la nieve me enfada, y el rocío tierno y la escarcha helada.

$[\ldots]$

Por ti, en el verano, huyo el sol ardiente, ¡mira qué inhumano y fiero accidente!

Busco alegres sombras con este cuidado, por verdes alhombras del hermoso prado $^{70}$.

Además Cardenio ridiculiza eficazmente otros tópicos de la lírica amorosa, como el de los tormentos de los celos, que "el Rústico" no sufre, pues, explica:

Mi amor entretuve con tantos consuelos que en mi vida tuve disgusto por celos.

Como he pretendido tenerte por buena, jamás he [temido] competencia ajena ${ }^{71}$. 
Es decir, también en este caso Cardenio viola abiertamente los preceptos del amor petrarquista: ni ha profesado dedicación exclusiva a la bella (los "consuelos" parecen aludir a aventuras amorosas con otras damas) ni idolatra a la amada, a la que solamente ha "pretendido" tener "por buena", ni teme celos, pues la dama no es en realidad excelente. Estas humoradas tienen en común con las de Burguillos su espíritu paródico y carnavalesco, pero también incluso la temática concreta. Es decir, Cardenio y Burguillos coinciden en las convenciones que ridiculizan: la ya citada de la enfermedad de amor, el tópico de la mariposa y la llama ${ }^{72}$, la idea de que los prados florecen cuando los pisa la bella ${ }^{73}$, o el tópico de que el poeta está irreconocible debido a sus sufrimientos, que Burguillos resume en un ingenioso soneto ("Pregónase el poeta porque no se halla a sí mismo") ${ }^{74}$ y que Cardenio ridiculiza diciendo que ha llegado a tal punto que solo

dirá quién soy

quien me conociere ${ }^{75}$.

En suma, Cardenio se revela como un proto-Burguillos tanto por su función cómica y de contrapunto como por estilo, por su parodia de las convenciones de la lírica amorosa.

Otros pasajes que revelan la íntima conexión del Rústico con Burguillos son las tertulias en prosa que pueblan la Arcadia. En estas discusiones Cardenio desempeña constantemente su papel carnavalesco, rebajando

72 Ibidem, 269v. La tópica imagen de la mariposa o polilla y el fuego aparece ridiculizada por el Rústico, que declara acercarse al fuego por ser invierno. En las Rimas de Tomé de Burguillos se encuentra parodiada en el soneto número 3, Lope de Vega, Rimas de Tomé, vv. 7-8. Según la convención petrarquista, la imagen simboliza la situación fatal del amado, R. O. Jones, "Renaissance Butterfly, Mannerist Flea: Tradition and Change in Renaissance Poetry", Modern Language Notes, LXXX (1965), pp. 166-184; María Pilar Manero Sorolla, Imágenes petrarquistas en la lírica española del Renacimiento. Repertorio, Barcelona, Promociones y Publicaciones Universitarias, 1990, pp. 313-317; Alan S. Trueblood, "La mariposa y la llama: motivo poético del Siglo de Oro", Letter and Spirit in Hispanic Writers: Renaissance to Civil War. Selected Essays, Londres, Tamesis, 1986, pp. 26-34.

73 Lope de Vega, Arcadia, f. 270v. Lope de Vega, Rimas de Tomé, núm. 148.

74 Ibidem, núm. 17.

75 Ibidem, Arcadia, f. 270v. 
el tono idealista de los galantes pastores que le acompañan y poniendo de relieve, o incluso ridiculizando, su estilo y razonamientos. El mejor ejemplo aparece en el libro tercero de la Arcadia, en el que Cardenio interrumpe una erudita discusión sobre la poesía, que los otros pastores han aderezado ricamente con citas de los clásicos y referencias a la inspiración divina que mueve a los poetas. Cuando los pastores peroran sobre la necesidad de una poesía que contenga, en proporciones semejantes, erudición (arte) e ingenio (naturaleza), el Rústico interviene poniendo en solfa el decoro de la lírica amorosa. Primeramente, Cardenio toca una nota muy típica de Burguillos, señalando que la mayoría de los que autodenominan poetas no merecen ese nombre ${ }^{76}$ :

No sé qué os decís -replicó el Rústico- de arte y naturaleza, que yo he visto muchos que sin saber de lo primero lo que mi mastín sabe de canto de órgano, ni tener de lo segundo más que mi manso de tañer vigüela de arco, han encarecido el papel a puros encarecimientos de propias fatigas y ajenas ingratitudes ${ }^{77}$.

Además, y también anticipando el estilo de Burguillos, Cardenio pone en evidencia las convenciones del género, los "encarecimientos de propias fatigas" que hemos analizado anteriormente al tratar la enfermedad de amor, y las "ajenas ingratitudes", el manido topos de la belle dame sans merci. Igualmente ridículo y propio de Burguillos es el campo semántico prosaico y la carnavalización, pues Cardenio recurre a comparaciones con animales, un mastín y un manso. A continuación, el Rústico lleva adelante su crítica desvelando, como avanzamos antes, que la lírica amorosa no se sostiene en el decoro, en la adecuación de estilo y destinatario:

De los cuales soy yo uno, que con el natural que veis y el arte de guardar cabras hice el otro día una elegía a mi dama, sin invocar a Febo ni a Melpómene, ni mojar los labios en la fuente Cabalina, que no es menes-

76 A este tema de la increíble abundancia de poetas Burguillos le dedica varios sonetos en 1634. Valga como ejemplo el número 81: "De la buena cosecha de poetas conforme al pronóstico de los almanaques", Lope de Vega, Rimas de Tomé, op. cit., núm. 81.

77 Lope de Vega, Arcadia, f. 165v. 
ter mucha filosofía ni cosmografía para el entendimiento de una mujer, que antes huyen de tanta metafísica como en esos vuestros ingenios hallaréis a cada paso $^{78}$.

De modo cómico, el Rústico rebaja a los poetas mencionándose a sí mismo tras el mastín y el manso, como si estuviera descendiendo en la escala de ingenios: perro, borrego, pastor rústico metido a poeta. Además, Cardenio denuncia la cuantiosa erudición que adornaba la lírica áurea:

Contenteme yo con decille que me parecía la mujer más hermosa que hasta entonces había visto. Porque ¿qué se me da a mí de no saber a cuántos cielos está Saturno y en qué tiempo del año es el nacimiento de las Cabrillas, y si la Vía Láctea se llamó Galasia porque Faetón la abrasó cuando guiaba los caballos de su padre, y por la refración de las muchas estrellas que allí se juntan está de color blanca, y si se ve por la recepción de la lumbre en la exhalación caliente, seca y rara; o a qué mano cae la Libia, y si se engendran los ríos en los cóncavos de la tierra del aire detenido; cómo se sueña; en qué difieren el apetito sensitivo e intelectivo, y si se engendra amor por los espíritus delicados que engendró la vista; por qué es mudo el pez, canta el ave y el animal apetece la comida y huye del castigo? Sin otras cosas que los que las han dicho no las creen, porque no las vieron, y los que agora las leen no las buscan, porque saben que no las han de hallar; para venir a decir finalmente que amor es un deseo de lo que es hermoso y una común naturaleza de engendrar su semejante ${ }^{79}$.

La enumeración de Cardenio resulta ya de por sí ridícula, pues desvela hasta qué punto el ornato erudito se desvía del tema central de la lírica amorosa. Para el Rústico estos tópicos ${ }^{80}$ resultan contraproducentes, pues,

78 Ibidem, ff. 165v-166r.

79 Ibidem, ff. 166r-166v.

80 Especialmente manido, y especialmente cultivado por Lope, es el topos platónico de que el amor es deseo de hermosura. La fórmula se encuentra por toda la obra del Fénix, aunque su expresión más conocida es la del diálogo de los "villanos filosóficos" de Fuenteovejuna, ed. Donald McGrady, Barcelona, Crítica, 2001, vv. 381-426. Según afirma en el Isidro, ed. Antonio Sánchez Jiménez, Madrid, Cátedra, 2010, canto VII, vv. 71-75, Lope extrajo la idea de los Diálogos de amor de León Hebreo. El Rústico parece sugerir que tales ideas son tan comunes que no es necesario cubrirlas de tanta erudición. 
como indica, las mujeres no los entienden y más bien huyen de tanta metafísica. Es decir, estilo y destinatario no se corresponden, por lo que falla uno de los pilares de la escritura, el decoro. Frente a tal aparato, a Cardenio le parece mucho más eficaz encarecer directamente la hermosura de la dama, decirle que le "parecía la mujer más hermosa que hasta entonces había visto" ${ }^{81}$.

Se trata de comentarios tan típicos del estilo de Burguillos que no debería sorprender que el regocijado poeta tenga un soneto dedicado al mismo tema. En 1634, el jocoso licenciado sigue el ejemplo de Cardenio y denuncia la erudición de la poesía amorosa y su indecoroso contraste con su supuesto destinatario, la bella, que no tiene suficiente educación para comprender los rebuscados conceptos de los poemas que se le dedican. En el caso de Burguillos el contraste entre ornato y destinatario es aun mayor, pues la dama del licenciado es, recordemos, fregona:

\section{Dice cómo se engendra amor hablando como filósofo.}

Espíritus sanguíneos vaporosos suben del corazón a la cabeza, y saliendo a los ojos su pureza pasan a los que miran amorosos.

El corazón, opuesto, los fogosos rayos sintiendo en la sutil belleza, como de ajena son naturaleza, inquiétase en ardores congojosos.

Esos puros espíritus que envía tu corazón al mío, por estraños me inquietan como cosa que no es mía.

Mira, Juana, qué amor, mira qué engaños, pues hablo en natural filosofía a quien me escucha jabonando paños ${ }^{82}$. 
Los "espíritus" de Burguillos evocan un famoso poema de Garcilaso ${ }^{83}$, pero más que a Garcilaso en particular critican la excesiva e inútil erudición en general y la de los poetas cultos en particular. En contraste con Burguillos, Cardenio no fustiga a los cultos, pues en 1598 Góngora todavía no había escrito ni difundido sus innovadores epilios, la Fábula de Polifemo y Galatea y las Soledades. Más bien, "el Rústico" denuncia las convenciones que alimentan la lírica de su tiempo, anticipando así un estilo que años más tarde Burguillos blandiría contra Góngora y sus seguidores. De hecho, este énfasis en perseguir a los cultos es una de las características que Cardenio no comparte con Burguillos, pero al lector avisado no se le habrá escapado que también hay otras cualidades del personaje de 1634 que no aparecen en 1598: Cardenio no trata el tema del mecenazgo ni la temática religiosa o neo-estoica, y si alude a otras preocupaciones de Burguillos (la naturaleza divina de los poetas o la pobreza) es solo de modo indirecto y sin énfasis alguno.

Estas diferencias deben explicarse acudiendo al cambio de contexto e intenciones que Lope experimentó entre la Arcadia y las Rimas de Tomé de Burguillos, y debe servirnos como transición a la tercera sección de nuestro estudio: puesto que ya hemos examinado las características de Burguillos y las hemos contrastado con las de "el Rústico", conviene ahora interpretar esta conexión. Es decir, hemos comprobado que Cardenio es un proto-Burguillos, pues ambos son poetas regocijados cuyo carácter y bromas se basan en la parodia de las convenciones literarias del momento: Burguillos sería, pues, una reescritura y evolución del personaje que Lope incluyó en su primer libro publicado, la Arcadia. Sin embargo, este descubrimiento nos exige también indagar en la prehistoria y contexto de Cardenio, y no solo ya de Burguillos, para entender así mejor los motivos de las diferencias y semejanzas de estos dos personajes.

83 La explicación del proceso de enamoramiento y el tecnicismo "espíritu" aparece en el soneto VIII de Garcilaso de la Vega: "De aquella vista pura y excelente", Garcilaso de la Vega, Obra poética, núm. VIII. Como explica Herrera, el enamoramiento ocurre cuando unos sutiles espiritus con la imagen de la belleza salen de los ojos de la amada y entran por los del amante, desde donde bajan al corazón y encienden su sangre, Fernando de Herrera, op. cit., pp. 334-337. 
Para ello necesitamos en primer lugar reconocer la importancia de los años en que Lope ideó y comenzó a escribir la Arcadia, los de Alba de Tormes ${ }^{84}$, claves en la formación del escritor madrileño ${ }^{85}$. Esta estancia en Alba nos debe servir para intentar dirimir la cuestión acerca de los orígenes de Cardenio, a quien podemos adjudicar un origen ya libresco, ya teatral. Ambas facetas se conjugaban en el Lope que arribó en 1592 a Alba, pues antes de llegar al Tormes el Fénix ya era conocido como dramaturgo y ya había puesto en marcha los mecanismos de la comedia nueva. Además, desde Alba Lope continuó escribiendo para los corrales, e incluso es posible que para los salones del duque de $\mathrm{Alba}^{86}$. Pero la estancia a orillas del Tormes añadió a esta faceta dramática un componente de erudición que acompañaría de por vida a Lope: además de escribir comedias, en Alba el Fénix se dedicó a formarse usando la rica biblioteca del duque, como se deja ver, en primer lugar, en la Arcadia, cuya impresionante erudición no se limita en absoluto a las tan traídas y llevadas polianteas ${ }^{87}$. Es la faceta libresca que Lope mostraría al llegar la prohibición de representar comedias que se inició en noviembre de 1597 y que, según todas las apariencias, podía durar sine die: en esos años el Fénix preparó para la imprenta una monumental andanada de libros, intentando reubicar su fama de autor de comedias transformándose en autor de libros impresos. En suma, en el Lope de los años finales del siglo, los que vieron nacer a "el Rústico", el proto-Burguillos, el mundo de los libros se yuxtapone al de los corrales de comedias.

Esta doble haz de la carrera del autor nos remite a la posible doble genealogía del personaje de 1598, pues Cardenio puede ser heredero de

84 Donald McGrady, "Introducción”, Lope de Vega. Prosa, I. Arcadia. El peregrino en su patria, ed. Donald McGrady, Madrid, Biblioteca Castro, 1997, pp. XIV-XV.

85 La importancia del periodo de Alba para el desarrollo de la práctica teatral lopesca ya ha sido puesta de relieve por Jesús Cañas Murillo, "Lope de Vega, Alba de Tormes y la formación de la comedia”, Anuario Lope de Vega, VI (2000), pp. 75-92.

86 Dominic Finello, The Evolution of the Pastoral Novel in Early Modern Spain, Brepols, Arizona State University, 2008, p. 180. Joan Oleza, "La tradición pastoril en la comedia de Lope de Vega”, en José Luis Canet Vallés (ed.), Teatro y prácticas escénicas II: La comedia, Londres, Tamesis, 1986, pp. 325-335.

87 Rafael Osuna, "El Dictionarium de Stephanus y la Arcadia de Lope", Bulletin of Hispanic Studies, XLV (1968), pp. 265-269. 
los graciosos que pueblan las comedias, o de figuras librescas como los filósofos cínicos o Sileno. Ambas posibilidades resultan plausibles, y por tanto es necesario examinarlas con más detenimiento. En cuanto a la primera, la analogía entre "el Rústico" y el gracioso de la comedia ya ha sido percibida por los críticos que han estudiado la Arcadia, como Edwin Morby $^{88}$, Juan Bautista Avalle-Arce ${ }^{89}$ o Rafael Osuna ${ }^{90}$, pues, recordemos, Lope escribió también una comedia con ese título (La Arcadia), fechada en torno a 1610-1615, en la que Cardenio aparece como un personaje dramático muy semejante al de un gracioso ${ }^{91}$. De hecho, sería verosímil que Lope hubiera aportado a la novela pastoril una invención que él mismo había aportado primero ${ }^{92}$ y asentado después en la comedia nueva y que comenzaba a aparecer en escena precisamente en sus obras de los años 9093: el gracioso ${ }^{94}$, para algunos inventado precisamente en

88 Edwin S. Morby (ed.), Arcadia, de Lope de Vega Carpio, Madrid, Castalia, 1975, p. 21.

89 Juan Bautista Avalle-Arce, La novela pastoril española, Madrid, Revista de Occidente, 1959, p. 138.

90 Rafael Osuna, La Arcadia de Lope de Vega: génesis, estructura y originalidad, Madrid, Real Academia Española, 1972, p. 84.

91 Para Jesús Gómez, La figura del donaire o el gracioso en las comedias de Lope de Vega, Sevilla, Alfar, 2006, p. 26, que no argumenta en esta ocasión su afirmación, el Cardenio de La Arcadia no es un gracioso propiamente dicho.

92 La crítica viene atribuyéndole a Lope la invención del gracioso ya desde tiempos de Lord Holland, Some Account of the Lives and Writings of Lope Félix de Vega Carpio and Guillén de Castro, Londres, 1817, v. I, p. 219.

93 L. C. Poteet-Bussard, "Algunas perspectivas sobre la primera época del teatro de Lope de Vega”, en Manuel Criado de Val (ed.), op. cit., pp. $341-354$ (p. 351). José F. Montesinos, "Algunas observaciones sobre la figura del donaire en el teatro de Lope de Vega", en Estudios sobre Lope de Vega, Madrid, Anaya, 1967, pp. 21-64. H. Arjona, "La introducción del gracioso en el teatro de Lope de Vega", Hispanic Review, VII (1939), pp. 1-21. Aunque el propio Lope afirmara en la dedicatoria a La francesilla que fue en esa comedia (fechada en 1596) en la que se introdujo el personaje, Jesús Gómez ha demostrado que el personaje se encuentra en comedias muy anteriores, ya de comienzo de los años 90. Cf. Jesús Gómez, La figura, p. 13; p. 33; p. 59. Otros estudiosos, como Jesús Cañas Murillo, "Lope de Vega", p. 84, han afirmado también localizar graciosos en obras anteriores a La francesilla.

94 Empleamos la palabra "gracioso" en lugar de su sinónimo "figura del donaire" (Jesús Gómez, "Precisiones terminológicas sobre "gracioso" y "figura del donaire" (siglos XVI-XVII)", Boletín de la Real Academia Española, LXXXII (2003) pp. 233-257, 
estos años de $\mathrm{Alba}^{95}$ : Cardenio tiene mucho en común con los graciosos tempranos que pueblan las comedias del primer Lope ${ }^{96}$, e incluso con graciosos posteriores. Para empezar, el sobrenombre de "el Rústico" remite ya al mundo campesino y servil propio de la mayoría de los graciosos ${ }^{97}$, con los que además Cardenio comparte un sinfín de características: son esencialmente personajes cómicos y risibles, practican además frecuentemente un humor carnavalesco ${ }^{98}$, son materialistas ${ }^{99}$, intercalan reflexiones metaliterarias y parodias, así como ridículas interpretaciones literales ${ }^{100}$, rechazan constantemente el idealismo, están en relación de "dualismo

por la mayor difusión de la primera, pese a que tengamos indicios de que Lope consideraba "gracioso" un neologismo y prefería usar el segundo término.

95 Jesús Gómez, Lope de Vega, p. 60.

96 Sobre la práctica teatral del primer Lope, con bibliografía actualizada, conviene consultar el trabajo de Jesús Gómez, Individuo y sociedad en las comedias (15801604) de Lope de Vega, Madrid, Universidad Autónoma de Madrid, 2000.

$97 \mathrm{El}$ mundo rural y popular está siempre de trasfondo de la figura del donaire, aunque sea como origen último. Así lo han reconocido los críticos, ya para afirmar, como Noël Salomon, Lo villano en el teatro del siglo de oro, Madrid, Castalia, 1985, que el gracioso lopesco es de origen aristocrático y representa el punto de vista urbano, que se burla del campesino, ya para sostener, como que los graciosos y su humor son de origen popular. Cf. Maxime Chevalier, "El aldeano cómico en la comedia lopesca", en Y. R. Fonquerne (ed.), Risa y sociedad en el teatro español del siglo de oro. Actes du 3 e colloque du Groupe d'Etudes Sur le Théâtre Espagnol. Toulouse 31 janvier-2 février 1980, Toulouse, Sud, 1981, pp. 197-211). Una postura intermedia es la de Edwin Place, "Does Lope de Vega's Gracioso Stem in Part from Harlequin?", Hispania, XVII (1934), pp. 257-270. Más recientemente, Jesús Gómez, La figura, op. cit., p. 14; p. 26, se ha inclinado fuertemente por el origen urbano, en concreto de la servidumbre urbana. Afirma además que además habría que distinguir al verdadero gracioso de los simples o bobos rurales: "La comicidad de estos dos últimos tipos de personaje no es voluntaria sino inconsciente, como surgida de la propia "ignorancia simple"; a diferencia de lo que sucede con la comicidad ingeniosa de la que hace gala la figura del donaire" (Jesús Gómez, ibídem, p. 19). De la evolución del pastor bobo al gracioso se ha ocupado F. Cazal, "Del pastor bobo al gracioso: el pastor de Diego Sánchez de Badajoz", Criticón, LX (1994), pp. 7-18.

98 Alfredo Hermenegildo, Juegos dramáticos de la locura festiva. Pastores, simples, bobos y graciosos del teatro clásico español, Barcelona, Oro viejo, 1995, p. 10. Henryk Ziomek, Lo grotesco en la literatura española del Siglo de Oro, Madrid, Alcalá, 1983, p. 19.

99 Jesús Gómez, La figura, p. 89.

100 Ibidem, p. 83. 
complementario"101, con un personaje elevado (Anfriso, en el caso de Cardenio, Lope, en el caso de Burguillos, el amo, en el caso del gracioso teatral) del que suelen ser caricatura ${ }^{102}$, poseen la paradójica naturaleza de bobo-sabio, etc ${ }^{103}$. Este podría ser el caso, es decir, que el Rústico procediera de la figura teatral del gracioso, y que Tomé de Burguillos fuera entonces el último hito de un desarrollo teatral que Lope llevó desde las tablas (gracioso) a la narrativa pastoril (Cardenio) y a la lírica (Burguillos). En ese caso, la comparación entre Cardenio y Burguillos, con la necesaria exploración de las fuentes teatrales del primero, nos llevaría a concluir que la experiencia teatral del Fénix enriqueció géneros novelísticos y líricos.

La otra posibilidad es que Lope hubiera ideado la figura de Cardenio en medio de sus lecturas en Alba y que con ella hubiera enriquecido luego el naciente personaje del gracioso teatral. Esta alternativa también resulta plausible, y no solo porque la cuestión de la genealogía del gracioso sea un enigma todavía sin aclarar $^{104}$. Además, la simple lectura de la Arcadia revela que "el Rústico" tiene aires librescos que lo entroncan con la tradición humanista del tonto-sabio, personaje al que tanto recuerda Cardenio. Por ejemplo, cuando Frondoso describe a "el Rústico" sus palabras honrarían al mejor de los cínicos: "hombre de agradable naturaleza, jovial y alegre, y que ignora lo que quiere y sabe lo que ignoramos"105. Es decir, el Fénix podría haber construido a Cardenio inspirado por esa figura del filósofo cínico, tan de moda durante la primera mitad del siglo XVI, y que pudo haber encontrado en la lectura de Diógenes Laercio o de Ravisius Textor, probablemente en la biblioteca del duque. Esta hipótesis

101 Ibidem, p. 22; p. 63.

102 Ibidem, p. 29.

103 Sobre la figura del gracioso y sus características en general conviene consultar los estudios clásicos de José F. Montesinos, "Algunas", op. cit., Charles David Ley, El gracioso en el teatro de la península (siglos XVI-XVII), Madrid, Revista de Occidente, 1954, y Fernando Lázaro Carreter, "Funciones de la figura del donaire en el teatro de Lope", en Ricardo Doménech (ed.), El castigo sin venganza y el teatro de Lope de Vega, Madrid, Cátedra, 1987, pp. 31-49, así como el volumen colectivo editado por Luciano García Lorenzo, La construcción de un personaje: el gracioso, Madrid, Fundamentos, 2005. Excelente y actualizado es el reciente trabajo de Jesús Gómez, La figura.

104 Jesús Gómez, La figura, p. 11.

105 Lope de Vega, Arcadia, f. 232r. 
también se apoya en el parecido de "el Rústico" con una figura mitológica tradicionalmente asociada con los cínicos: Sileno. Como Sileno, Cardenio monta un ridículo asno al que adora y defiende como el más útil animal del mundo. Este asno le acompaña continuamente y casi parece un doble jocoso del ya cómico personaje: "Vieron bajar por las peñas a Cardenio el Rústico sobre su flaco asnillo, que, pisando las guijas y pizarras de los blandos arroyuelos que atravesaban la sierra, encaminado a la cueva, venía cantando así”106. Además, y sobre todo, Cardenio es como Sileno un personaje excéntrico de apariencia cómica, pero sabio y revelador de grandes verdades. Es decir, ya como Sileno, ya como cínico, "el Rústico" podría también remontarse a orígenes librescos muy distintos a la experiencia de los corrales de comedias ${ }^{107}$. En ese caso, el Fénix habría rumiado sus lecturas y experimentado con ellas en la Arcadia. Desde allí sus innovaciones se habrían desplazado primero a las tablas, solidificando (o creando) la figura del gracioso, y luego a la lírica, vestidas con la pobre sotana de Burguillos.

En suma, la comparación con el Cardenio de la Arcadia revela que Tomé de Burguillos, con su énfasis en la parodia y burla de las convenciones literarias, es uno más entre los varios casos de reescritura que encontramos en la obra y carrera de Lope. Cardenio el Rústico es un pastor alegre e inteligente, que con sus ingeniosas salidas de tono actúa como gracioso en la novela. Se burla con humoradas satíricas de las convenciones amorosas de temática y estilo en que se basa la Arcadia: las lágrimas masculinas, la enfermedad amorosa, las antítesis, la erudición de los poemas de amor, etc. Toca un tamboril destemplado con el que acompaña sus composiciones jocosas, pero, pese a su aparente rusticidad, da muestras en sus donaires de mucha erudición. Tiene un asno al que ama con extremo, y sobre el que se sienta con ciertas reminiscencias de Sileno, aunque también tiene mucho en común con el gracioso de los corrales, desarrollado por el propio Lope.

El Rústico puede estar entroncado con esta figura del donaire teatral, o bien con las lecturas del Fénix en Alba, o bien con ambas fuentes,

106 Ibidem, f. 268v.

107 Este contraste entre corrales y erudición no es por supuesto total, pues las innovaciones de la comedia nueva le debían mucho al teatro clásico y a la tragedia renacentista, L. C. Poteet-Bussard, op. cit., p. 341. 
pero lo cierto es que Cardenio, el proto-Burguillos que hemos descubierto, fue esencial en la carrera del Fénix. Con Cardenio Lope inició una vena burlesca que le permitiría desatar su humor y furia contra los cultos gongorizantes a partir de los años veinte del siglo XVII. Además, su figura le abriría al autor la posibilidad de encarnarse en un personaje cómico, como hiciera con Burguillos. Porque Tomé de Burguillos no fue el único disfraz que adoptó en vida Lope, que ya se había vestido de don Carnal en una célebre ocasión en las fiestas de Denia. En esas celebraciones, y como analiza Elizabeth Wright ${ }^{108}$, Lope logró dirigirse en persona y en público a Felipe III, aunque para lograrlo tuvo que vestirse en hábito bufonesco y aprovechar un contexto propio de carnaval, como relata el cronista Felipe de Gauna:

Iban delanteras dos máscaras ridículas, que una de ellas fue conocida por el poeta Lope de Vega, el cual, vestido de botarga, hábito italiano, que era todo de colorado, con calsas y ropilla seguidos y ropa larga de levantar, de chamelote negro, con una gorra de terciopelo claro en la cabeza, y éste iba a caballo, con una mula baya ensillada y a la jineta y petral de cascabeles, y por el vestido que traía y arsones de la silla, levaba colgados diferentes animales de carne para comer, representando el tiempo de carnal, como fueron muchos conejos, perdices y gallinas y otras aves, colgadas por el cuello y cintura de su cuerpo, que había mucho que mirar en él ${ }^{109}$.

"Mucho que mirar" había, en efecto, en el traje del poeta, como también lo había en el que traía Cardenio en el combate naval de la Arcadia: "Seguíale la barca de Cardenio el Rústico, tan compuesta de comida y diversidades de frutas como se suelen ver de populosas ciudades las proveídas plazas en años fértiles" 110 . Es decir, Cardenio es el primer eslabón en una cadena de textos que culmina en las Rimas de Tomé de Burguillos, pero que afecta a momentos clave en la carrera de Lope. El Fénix usó este personaje durante toda su carrera para alcanzar diversos objetivos literarios y profesionales: renovar los libros de pastores, reescribir su imagen pública, fulminar

108 Elizabeth R. Wright, From Pilgrimage, pp. 50-51.

109 Emilio Orozco Díaz, Lope y Góngora frente a frente, Madrid, Gredos, 1973, p. 107. 110 Lope de Vega, Arcadia, ff. 245v-246r. 
Antonio Sánchez Jiménez, Cardenio “el Rústico”, el licenciado Tomé de Burguillos...

contra los cultos o renovar la lírica áurea desde una posición medio jocosa medio desengañada. Cardenio, el proto-Burguillos, es esencial para comprender la obra de Lope. 